\title{
Barcode Recognition Techniques: Review \& Application
}

\author{
Nikash Pradhan ${ }^{1}$, Dr. Rajesh Kumar Tyagi ${ }^{2}$, Ms. Pooja Nagpal ${ }^{3}$ \\ ${ }^{1,2,3}$ Department of Computer Science \& Engineering, College of Computer Science and Engineering, Amity University, \\ Haryana, India \\ Correspondence should be addressed to Nikash Pradhan; pradhannikash97@gmail.com
}

Copyright $\odot 2021$ Nikash Pradhan et al. This is an open access article distributed under the Creative Commons Attribution License, which permits unrestricted use, distribution, and reproduction in any medium, provided the original work is properly cited.

\begin{abstract}
Because of the importance of maintaining track of all products in one location, barcodes have become important elements of sales and product services. Many methods have been developed to make the task of reading barcodes more user-friendly. This project aims to use image processing as a technique for recognizing the barcode using the camera. Using this technique, the machines will be able to read the barcode using the camera and can decode the information on the barcode using the software capable of image processing [1]. The platform will be created for the MATLAB software package and will function with a webcam or digital camera as an interface. On the Graphical User Interface, the device can analyse the image and display the barcode type, data, and image size (GUI) [1]. The machine is designed to identify different types of barcodes and display the data if the barcode image is obtained. The machine is also intended to provide a more convenient and cost-effective way of viewing data from barcodes than electronic barcode scanners. An individual who wants to inspect data identified by barcode numbers without having to go to a location that provides barcode scanner services can use this computer at any time and from any location [1]. As a result, the project has gone smoothly and without a hitch. It is advised that the computer have a slider so that the user can change the brightness of the image captured by the webcam for future device enhancement.
\end{abstract}

KEYWORDS- Barcode, Graphical User Interface, MATLAB, Recognize, Product.

\section{INTRODUCTION}

A barcode is a visual representation of information on a surface made up of bars and spaces [1]. These bars and spaces have varying widths, making them distinct, and they're encoded with alphanumeric characters and symbols like a question mark, hyphen, and so on. Knowledge is represented using various variations of these alphanumeric characters. Different forms of barcodes, such as Code 128, Code 39, EAN, and so on, are used today (Brain, 2000) [1]. The success in barcode technology has been built on the ability to fit more information into the shortest amount of space possible. Barcodes are often used in bookstores and grocery stores today to maintain track of available products and make food checkout easier. Barcodes are rectangleshaped markings made up of thin or thick parallel black or blue lines that are parallel to each other. Barcodes allow data entry into computers to be automatic and fast. Since the last decade, barcodes have been used in a variety of applications, from retail goods and mobile devices. The commodity reference number is printed on the lines of barcodes. These details should be registered in computers so that each commodity can be counted individually for business profits and purchases. When reading barcodes on goods using a laser scanning unit, the machine generates a signal that is interpreted in the computer by software. This information is then used to determine which product to purchase. This approach allows companies to sell their products in a timely and reliable manner. In today's business world, there are several different types of barcodes. The technological features of a particular type of barcodes, such as bar width, character set, encoding mechanism, and checksum parameters, are specified by a barcode symbology. [1]. There are four types of barcodes namely numeric-only barcodes this barcode contains only numerical values, alpha-numeric barcodes this barcode contain alphanumeric values, 2D barcodes this barcode is of a different type in may contain alphanumerical values and is also called a QR code, and industry standards for barcodes and labels. Thresholding is one of the elements to remember when describing an image, just as it is in image processing. Thresholding is the most fundamental form of image segmentation.

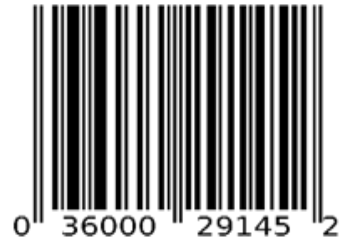

Fig. 1: 1D Barcode [2]

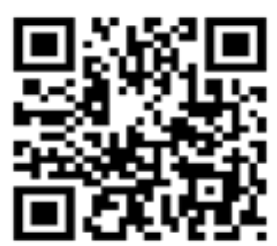

Fig. 2: 2D Barcode [2]
Thresholding can be used to create binary representations out of grayscale images. Individual pixels in an image are classified as object pixels if their colour reaches any threshold value (assuming the object is lighter than the background), and background pixels if their colour does not exceed any threshold value [1]. This is known as the threshold above convention. Threshold below is the opposite of a threshold above; threshold inside is where a pixel is labelled "object" if its value is less than two thresholds, and threshold outside is the inverse of threshold within. A value of "1" is typically assigned to an object pixel, while a value of " 0 " is typically assigned to a 
background pixel. After the value is assigned, a binary image is generated by creating each pixel white or black according to its values.

\section{LITERATURE REVIEW}

QR (Quick Response) code recognition from an image, which can be used to insert the image into a QR code reader [5]. The code can identify the image and retrieve the portion of the file, which can include details about specific individuals and organization logos, for example. The QR code is located in this section. Barcodes are of two types i) 1D barcode and ii) 2D Barcode. 1D Barcode encodes the information or data between the parallel lines and spaces between them, these parallel lines have different widths and different spaces between them. A 1D barcode can only store the alphanumerical data if more information is to be stored then the length of the barcode should be increased [5]. When a barcode reader device scans the barcode, the reader uses a laser to read those unique parallel lines and spaces. The barcode reader reads the code from left to right when scanning it. After that, the barcode reader reads the pattern of shaded lines on the black and white bar and converts the encoded data into binary code. After the information is extracted into a binary form the computer reads the binary codes and the decoded information or data is displayed in the screen of the computer screen. Barcodes are made up of 95 blocks out of those 95 blocks barcodes are written in 12 blocks. Three blocks are designated as a left guard, center guard, and right guard among the 95 total blocks [3]. The barcodes are designed in such a way that they can categories the type of product. It can determine the materials that the product is made up of, it also determines that the product is vegan or non-vegan. Barcodes are the combination of different types of information which includes country code, manufacture's code, product code, and check digits, the first three digits determine the country code, the next four digits determine the manufacture's code, next five digits determines the product code, and the last digits is a check digit. A barcode scanner is made up of a mirror, a light source, and a light sensor that can convert optical impulses into electrical signals. A barcode scanner decodes information by analysing image data generated by the light sensor and sending the data to the output port. The decoder is used to recognize the barcode symbols and it translates the parallel lines and spaces into the data in such a format that can be understood by humans [3]. Decoders can also store the data in access or an excel database. This technology is very beneficial for the current world as it can help in reducing the need for manual data collection and also helps in reducing the chances of human errors. This technology helps in quickening tasks like managing assets, performing point-of-sale transactions, and tracking inventories.

\section{METHODOLOGY}

A barcode scanner is used in scanning a barcode and retrieving the encoded information or data in the barcode. Barcode Sensor, and the decoder. A barcode scanner scans the barcode by scanning the parallel black and white bar and spaces by illuminating the barcode symbol with red light [3]. The illuminated light is reflected towards the sensor present in the barcode scanner. The sensor detects the reflected light and generates the analog signal from the illuminating reflected light, the decoder receives the produced analog signal, the decoder then interprets the analog signal and checks the barcode for validity using the check digit. After the validation of the barcode is done the decoder converts the barcode into text where humans can understand. The text that is decoded is sent to the computer system using the appropriate software that can communicate between the computer system and the barcode scanner. There is different type of barcode scanner which use different ways for scanning the barcodes and they have their advantages and disadvantages. Each type of barcode scanner is used to serve its specific purpose. Barcodes are generated by using some of the standards. The barcode symbols are categories into three sections left guard, center guard, right guard. The left guard consists of manufacturer code, the center guard consists of product code, and the right guard is a check bit.

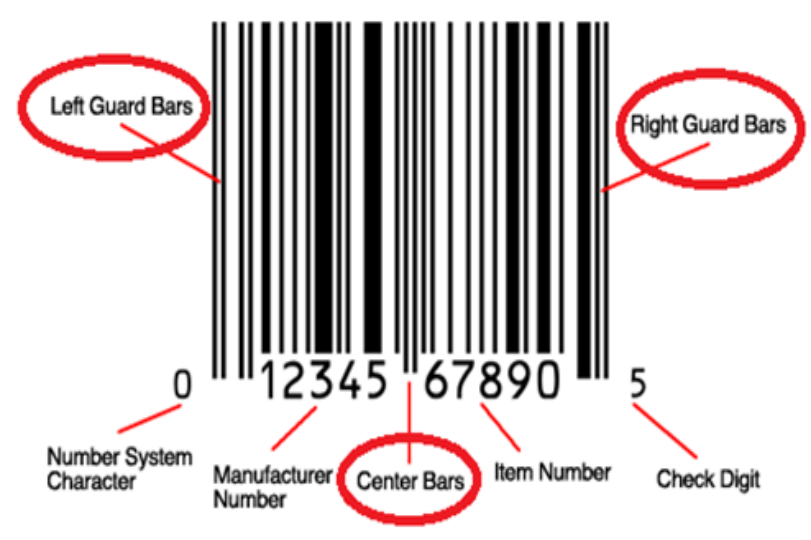

Fig. 3: Showing the detailed structure of the barcode [3]

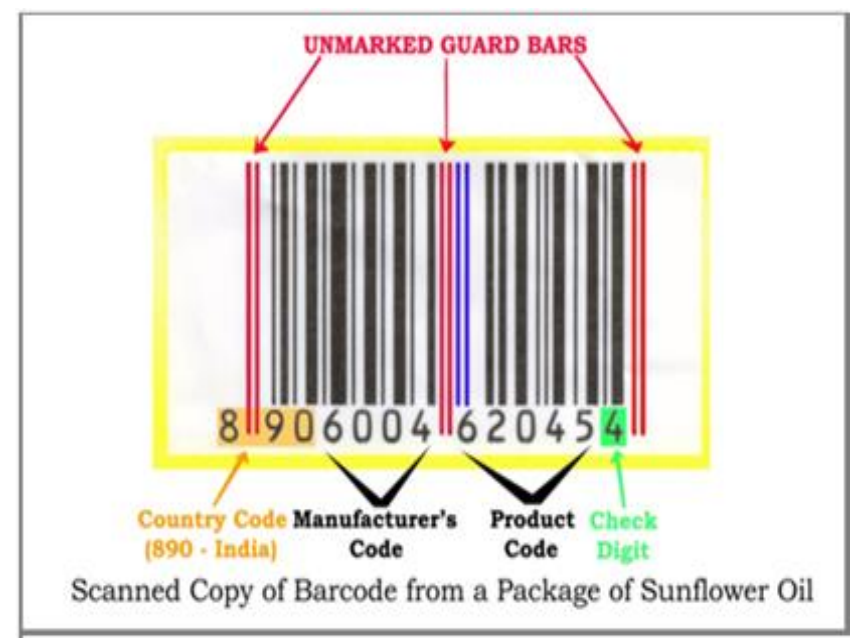

Fig. 4: Number representing its categories [3] 


\section{DIFFERENT TYPE OF BARCODES}

There are generally two types of barcodes 1 Dimensional and 2 Dimensional, there are also some categories under them which are explained in the below-given table:

Table 1: Different types of 1 Dimensional Barcodes

\begin{tabular}{|c|c|c|c|c|}
\hline \multicolumn{5}{|c|}{1 Dimensional } \\
\hline Code 39 & Code 128 & Interleaved 2 to 5 & $\begin{array}{l}\text { Universal Product } \\
\text { Code (UPC) }\end{array}$ & $\begin{array}{c}\text { International Article } \\
\text { Number (EAN) }\end{array}$ \\
\hline $\begin{array}{l}\text { Code } 39 \text { is the oldest } \\
\text { type of barcode [6] }\end{array}$ & $\begin{array}{l}\text { It is a highly dense } \\
\text { linear barcode }\end{array}$ & $\begin{array}{l}\text { It is a low dense } \\
\text { linear barcode }\end{array}$ & $\begin{array}{l}\text { It is a code usually } \\
\text { found in a product }\end{array}$ & $\begin{array}{l}\text { It is considered as a } \\
\text { superset of UPC }\end{array}$ \\
\hline $\begin{array}{c}\text { It is the first } \\
\text { alphanumeric type of } \\
\text { barcode. }\end{array}$ & $\begin{array}{l}\text { It is used in an } \\
\text { application where a } \\
\text { large no of data has to } \\
\text { be stored in a small } \\
\text { space }\end{array}$ & $\begin{array}{l}\text { It is used in } \\
\text { manufacturing, } \\
\text { distribution, } \\
\text { warehouse, etc. }\end{array}$ & $\begin{array}{l}\text { It is used in a } \\
\text { product by the } \\
\text { manufacturing } \\
\text { companies to } \\
\text { identify the product }\end{array}$ & $\begin{array}{l}\text { It is generally used in } \\
\text { books to tracks books }\end{array}$ \\
\hline It is developed in 1974 & $\begin{array}{c}\text { It was created in the } \\
\text { early } 1980 \mathrm{~s}\end{array}$ & $\begin{array}{c}\text { It is developed in } \\
1972\end{array}$ & $\begin{array}{c}\text { It is developed in } \\
1974\end{array}$ & $\begin{array}{c}\text { It is developed in } \\
1970\end{array}$ \\
\hline $\begin{array}{l}\text { It is used in electronics, } \\
\text { healthcare, and } \\
\text { government [6] }\end{array}$ & $\begin{array}{l}\text { It is mostly used in } \\
\text { the shipment of goods } \\
\text { in a courier. }\end{array}$ & $\begin{array}{l}\text { It is mostly used in } \\
\text { the shipment of goods } \\
\text { in a courier. }\end{array}$ & $\begin{array}{l}\text { It is mostly used in } \\
\text { a retail shop to } \\
\text { identify the product }\end{array}$ & $\begin{array}{l}\text { It is mostly used in } \\
\text { libraries, universities } \\
\text { to track books }\end{array}$ \\
\hline $\begin{array}{c}\text { It consists of } 5 \text { bars } \\
\text { and } 4 \text { spaces in which } \\
3 \text { are wide for binary } \\
\text { value } 1 \text { and } 6 \text { are } \\
\text { narrow for binary value } \\
0\end{array}$ & $\begin{array}{l}\text { It consists of } 3 \text { bars } \\
\text { and } 3 \text { spaces the bars } \\
\text { and spaces have } 4 \\
\text { different widths }\end{array}$ & $\begin{array}{l}\text { It consists of } 5 \text { bars } \\
\text { and } 5 \text { spaces } 2 \text { bars or } \\
\text { spaces are wide and } \\
\text { three are narrow }\end{array}$ & $\begin{array}{l}\text { It has } 30 \text { bars along } \\
\text { with white spaces }\end{array}$ & $\begin{array}{c}\text { It has } 30 \text { bars along } \\
\text { with white spaces }\end{array}$ \\
\hline $\begin{array}{l}\text { It can contain } 43 \\
\text { different alphanumeric } \\
\text { as well as space and } \\
\text { capacity to encode all } \\
128 \text { ASCII character }\end{array}$ & $\begin{array}{c}\text { It can contain } 107 \\
\text { patterns along with a } \\
\text { string of data, module } \\
103 \text { check digit }\end{array}$ & $\begin{array}{l}\text { It can encode only } \\
\text { numerical values and } \\
\text { the value should be } \\
\text { paired; numbers of } \\
\text { numerical values } \\
\text { should be even }\end{array}$ & $\begin{array}{l}\text { It encodes } 12 \text { digits } \\
\text { of numerical values }\end{array}$ & $\begin{array}{l}\text { It encodes } 13 \text { digits of } \\
\text { numerical values }\end{array}$ \\
\hline $\begin{array}{l}\text { This code does not } \\
\text { require the check digit }\end{array}$ & $\begin{array}{l}\text { This contains the } \\
\text { check digit }\end{array}$ & $\begin{array}{c}\text { This contain check } \\
\text { digits }\end{array}$ & $\begin{array}{l}\text { It contains check } \\
\text { digits }\end{array}$ & $\begin{array}{c}\text { It contains check } \\
\text { digits }\end{array}$ \\
\hline
\end{tabular}

Table 2: Different type of 2-Dimensional Barcodes

\begin{tabular}{|c|c|c|}
\hline \multicolumn{3}{|c|}{2 Dimensional } \\
\hline PDF417 & Data Matrix & Quick Response (QR) Codes \\
\hline It is a Stacked linear 2D barcode & $\begin{array}{l}\text { It is a Square shaped 2-dimensional } \\
\text { barcode }\end{array}$ & $\begin{array}{l}\text { It is Square shaped 2-dimensional } \\
\text { barcode that is mostly used in the } \\
\text { marketing sector }\end{array}$ \\
\hline It is developed in 1992 & It is Developed in 1994 & It is Developed in 1994 \\
\hline $\begin{array}{l}\text { It is mostly used for identification } \\
\text { such as in boarding pass, driving } \\
\text { license, etc. }\end{array}$ & $\begin{array}{l}\text { It is mostly used in electronics, } \\
\text { manufacturing, and healthcare system }\end{array}$ & $\begin{array}{c}\text { It is used in sharing the links, websites } \\
\text { URL, and storing information like in } \\
\text { aadhaar card }\end{array}$ \\
\hline $\begin{array}{l}\text { It is capable of encoding more than } \\
\text { one data files }\end{array}$ & $\begin{array}{c}\text { It is capable of encoding } 2000 \\
\text { characters }\end{array}$ & It can store up to 4000 characters \\
\hline $\begin{array}{c}\text { It can expand in size with } 4 \text { times than } \\
\text { the QR code }\end{array}$ & $\begin{array}{l}\text { It can expand in size as the } \\
\text { requirement for the manufactures }\end{array}$ & $\begin{array}{l}\text { It can expand according to the } \\
\text { required size }\end{array}$ \\
\hline
\end{tabular}




\section{TYPES OF BARCODE SCANNER}

\section{A. Pen-type readers}

Pen type reader is the type of barcode scanner where it uses reflection technology for reading the barcode. It consists of a light source and a light sensor or a photodiode, the light source and the photodiode is placed side by side of each other on the tip of the pen [2]. The light from the source hit the barcode and some of the light is absorbed by the barcode and some are reflected towards the photodiode, as black colour absorbs the light and white colour reflects light, a black bar in the barcode absorbs the light and space between them are which reflects the light to the photodiode. The photodiode identifies the bar and space using the waveform that measures the bar and the spaces that are in the barcode [2]. In the waveform generated by the photodiode, the voltages waveform is checked which helps in representing the bar and spaces in the barcode.

To use this type of barcode scanner the person using this pen has to move the pen at the uniform speed across the barcode that is to be scanned.

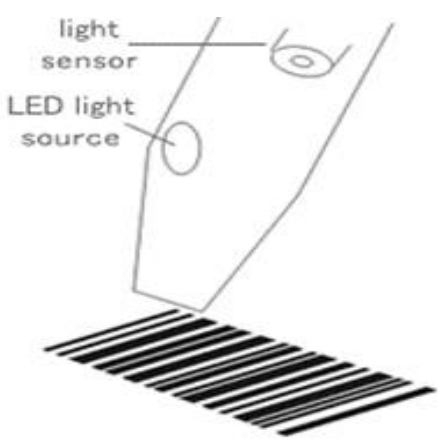

Fig. 5: Pen type Barcode Scanner [4]

\section{B. Laser Scanners}

A laser scanner works the same way as of pen-type scanner it also uses a light source and a photodiode to read the barcode but instead of light it uses a laser beam that is hit to the barcode and the reflected beam is captured by the photodiode [2]. It has an oscillating mirror that moves to scan the barcode from the front to the back of the barcode. The photodiode then checks the intensity of the reflected beam in the form of a waveform and the bars and spaces of the barcode are represented.

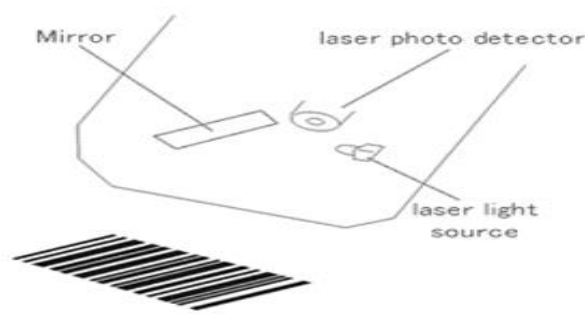

Fig. 6: Laser Barcode Scanner [4]

\section{CCD Reader}

CCD (Charge Coupled Device) is a type of barcode scanner that is similar to the digital camera, they capture the image of the barcode, they have hundreds of tiny photodiodes that capture the images [7]. Unlike pen-type and laser barcodes, it does not produce light and reads the barcode by checking the intensity of the voltage waveform. Instead of that, it measures the intensity of the emitted ambient light from the barcode [7]. This type of scanner is faster than the pen-type and the laser type, but cannot be used for scanning the far distance barcodes. This scanner requires a sufficient amount of light in the barcode to read the image.

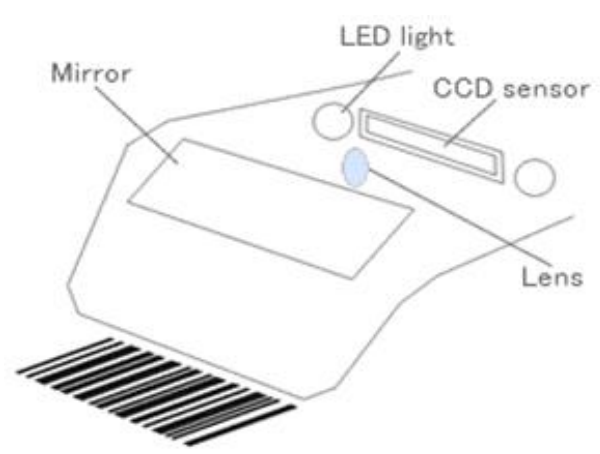

Fig. 7: CCD Barcode Reader [4]

\section{RESULT AND DISCUSSION}

Using this technology of recognition of barcode, a project has been implemented, where the camera of the mobile phone is used to scan the barcode, and with the help of the software, the barcode is decoded. The project which is implemented is the Point of sale system, which is an android application that can be used by the small retailer to manage their inventories, seamlessly sell the product by scanning the barcode of the product and getting the required information of the given product. This app has been developed using java programming in the android studio environment. This application helps the retailer in managing their inventories, keeping a record of sales and profit earned on a particular day, can identify if the product from the store is missing or the product has been sold by skipping the point of sale system. There was a traditional POS system used in the market but as it was heavy and requires more spaces and also requires lots of hardware like a monitor, barcode scanner, POS System, and the constant electricity to run the POS system, and was also much expensive as compared to mobile POS system. Mobile or android based POS system is much cheaper and easy to use, it does not take much space as compared to the traditional POS System. The only requirement for using the mobile POS system is the Android Mobile phone which has camera support and the latest version of Android that meets the minimum requirement for the POS system to get installed on the mobile phone, the minimum requirement of the mobile phone to support the POS system are the camera should be more the 5 Megapixel and the processor should be an octa-core processor. 
Here are some images of the project the is made by using the Barcode recognition system:

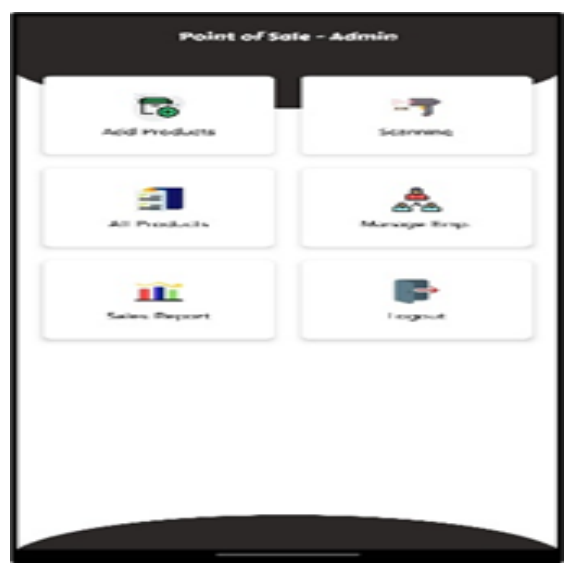

Fig. 8: This figure represents the admin page of the project where the admin can manage the employee or retailer and add the product and its details using the barcode scanner.

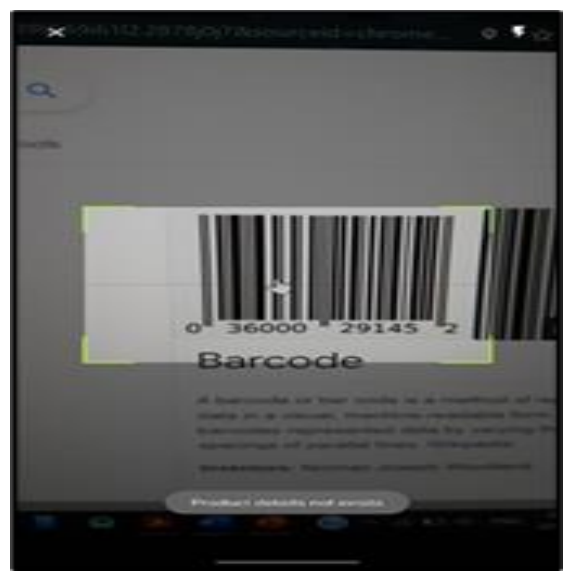

Fig. 9: This figure represents the screen where the retailer or an admin is scanning the barcodes to add the product or identifying the product using the point of sale app.

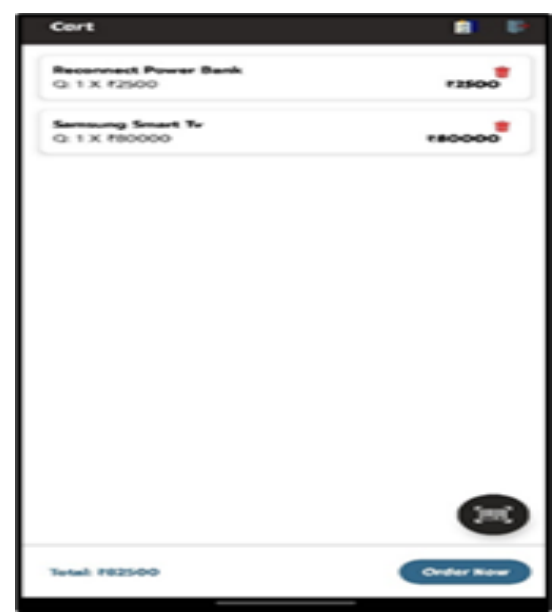

Fig. 10: This Figure represents the page where the retailer scans the barcode of the product and the product automatically gets identify with the help of the barcode and adds the product to the cart.

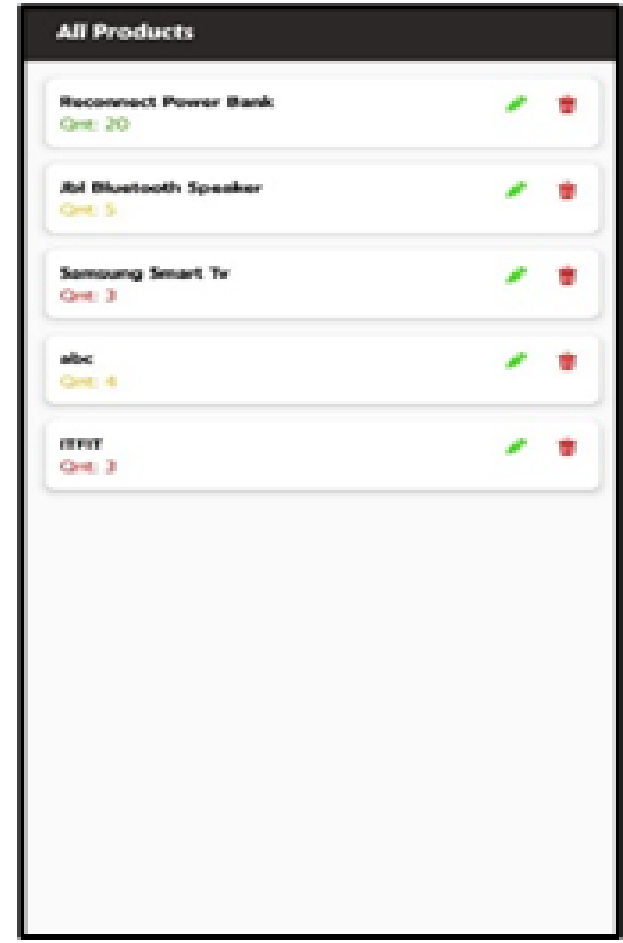

Fig. 11: This Figure represents the page of the admin section where it shows the product that has been registered in the POS system using the barcode found in the product.

\section{Benefits of using Mobile POS System as compared to Traditional System.}

Table 3: Traditional POS V/s Mobile POS.

\begin{tabular}{|c|c|}
\hline Traditional POS & Mobile POS \\
\hline $\begin{array}{c}\text { In a traditional POS } \\
\text { system, the information } \\
\text { of the Product is stored } \\
\text { in the same physical } \\
\text { system in which POS } \\
\text { System is installed. }\end{array}$ & $\begin{array}{c}\text { In a Mobile POS } \\
\text { system, the information } \\
\text { of the product is stored } \\
\text { in the server of the POS } \\
\text { provider. }\end{array}$ \\
\hline $\begin{array}{c}\text { The Traditional POS } \\
\text { system is much more } \\
\text { expensive in } \\
\text { comparison to the } \\
\text { Mobile POS System. }\end{array}$ & $\begin{array}{c}\text { Mobile POS System is } \\
\text { much cheaper in } \\
\text { comparison to that of } \\
\text { the traditional POS } \\
\text { System. }\end{array}$ \\
$\begin{array}{c}\text { Traditional POS system } \\
\text { requires lots of } \\
\text { hardware to run the } \\
\text { process. }\end{array}$ & $\begin{array}{c}\text { Mobile POS system } \\
\text { does not require lots of } \\
\text { hardware it only } \\
\text { requires the android } \\
\text { based mobile phone. }\end{array}$ \\
\hline $\begin{array}{c}\text { Traditional POS } \\
\text { systems are not easy to } \\
\text { make an update to the } \\
\text { system. }\end{array}$ & $\begin{array}{c}\text { Mobile POS systems } \\
\text { are much easy to make } \\
\text { and update. }\end{array}$ \\
\hline
\end{tabular}

The Figure 11 below represent the advantages of using a Mobile POS system rather than using a Traditional System. 


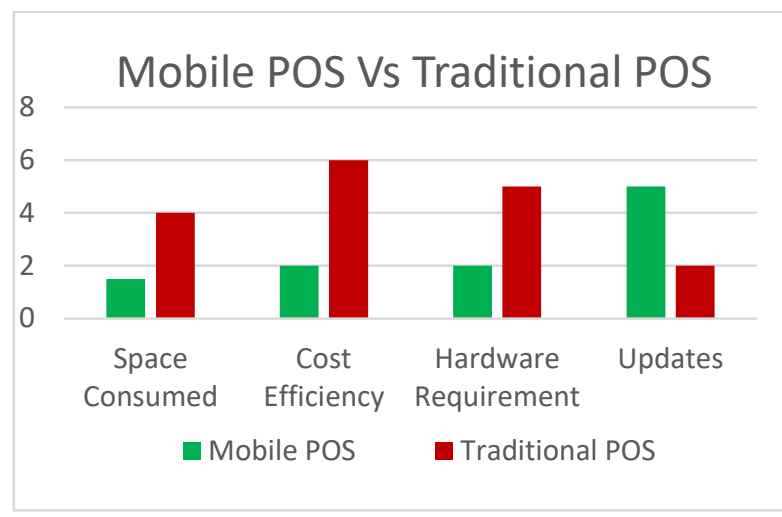

Fig. 11: Comparison between Mobile POS and Traditional POS System.

\section{CONCLUSION AND FUTURE SCOPE}

This presented paper reviews the technology about the barcodes like how they are created, what are their type, which types and how much data can a barcode store, and the several scanners and their method of recognizing the barcode. The barcode is a symbological representation of the encoded information or the data that can be scanned by the barcode scanner in a fast, accurate, and efficient way, before this technology people used to do the data entry task manually and managing the items with their serial no was also done manually, during this process lot of time is consumed and there was a high chance of human errors. To overcome this problem this technology was introduced where the serials no. or the unique no. that can be used to identify the product is encoded in a barcode so it can be understood by the computer system. This symbological representation of information called barcode can store several types of characters, symbols, and links to the websites. This technology is generally used everywhere in the modern world to make the data entry, searching, tracking of items simpler. This technology is mostly used by Courier service, Library in universities, Flight Boarding pass, Aadhaar card, Student ID Cards, Point of Sale System, etc. This can read the encoded information at high speed and more accurate which makes the process faster and efficient. This technology will be useful shortly for many tasks to be done in the data entry sector and many organizations will be using this technology to increase their productivity and shipping the products all over the world.

\section{CONFLICTS OF INTEREST}

The authors declare that they have no conflicts of interest.

\section{REFERENCES}

[1] Norhashimah Mohd Saad, Barcode Recognition system, International Journal of Emerging Trends \& Technology in Computer Science (IJETTCS), www.ijettcs.org, Volume 2, Issue 4, July-August 2013.

[2] Brain M., 2000 'How UPC Barcodes Work?' http://electronics.howstuffworks.com/upc.htm, last viewed 7th November 2008

[3] W. Su, L. Ma, K. Hu and L. Zhang, "A research on integrated application of rfid-based lean manufacturing", Control and Decision Conference 2009. CCDC'09. Chinese, pp. 57815784, 2009

[4] A. Akbari, S. Mirshahi and M. Hashemipour, "Application of rfid system for the process control of distributed manufacturing system", Electrical and Computer Engineering (CCECE) 2015. 28th annual IEEE Canadian Conference on, 2015.

[5] S. Mirshahi, A. Akbari and S. Uysal, "Implementation of structural health monitoring based on rfid and wsn", Electrical and Computer Engineering (CCECE) 2015. 28th annual IEEE Canadian Conference on, 2015.

[6] R. Muniz, L. Junco, and A. Otero. A Robust Software Barcode Reader Using the Hough Transform. In Proc. of 1999 International Conference on Information Intelligence and Systems, pages 313-319. IEEE, IEEE Computer Society Press, 1999.

[7] P.B. Nagpal et al, "Architecture of Software Defined WideArea Network: A Review ", GRD journals, vol 5 issue 6, May 2020.

[8] P. Nagpal et al, "Health Monitoring Multifunction Band Using IOT “, Proceedings of International Conference on IoT Inclusive Life (ICIIL 2019), NITTTR Chandigarh, India ,2020, page no 159-165

[9] P. B. Nagpal et al, "Design and Development of Android based Multimedia Player, International Journal of Innovative Research in Computer Science \& Technology, vol, issue 3, May 2020

\section{ABOUT THE AUTHORS}

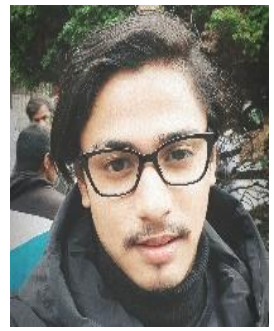

Nikash Pradhan, Master of Computer Applications, Bachelor of Computer Application. Computer Science and Engineering Student of Science Engineering and Technology Amity University Haryana, Amity Education Valley Gurugram, Manesar, Pachgaon, Haryana 122413

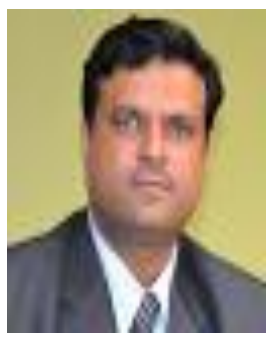

Dr. Rajesh Kumar Tyagi, $\mathrm{PhD}$ (Computer Science \& Engineering) M. Tech (Computer Science \& Engineering), B. Tech (Computer Science \& engineering). Assistant Professor Computer Science \& Engineering Faculty of Science Engineering and Technology Amity University Haryana, Amity Education valley, Pachgaon, Manesar, Gurugram, Haryana 122413

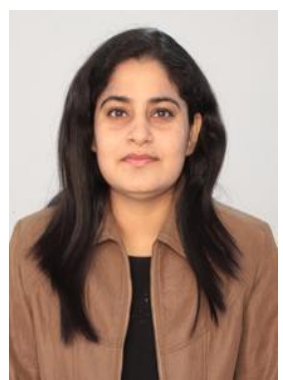

Ms. Pooja Nagpal, M. Tech (Computer Science \& Engineering), B. Tech (Computer Science \& engineering). Assistant Professor Computer Science \& Engineering Faculty of Science Engineering and Technology Amity University Haryana, Amity Education valley, Pachgaon, Manesar, Gurugram, Haryana 122413 